\title{
Pregnancy in phenylketonuria: dietary treatment aimed at normalising maternal plasma phenylalanine concentration
}

\author{
Geoffrey N Thompson, Dorothy E M Francis, Denise M Kirby, Robyn Compton
}

\begin{abstract}
The transport characteristics of the placenta, which favour higher phenylalanine concentrations in the fetus than in the mother, and regression data of head circumference at birth against phenylalanine concentration at conception in maternal phenylketonuria (PKU), suggest that treatment of maternal PKU should ideally aim to maintain plasma phenylalanine concentration within the normal range throughout pregnancy. A patient with classical PKU was treated from before conception by aiming to maintain plasma phenylalanine concentration within the range $50-150 \mu \mathrm{mol} / \mathrm{l}$ and tyrosine within the range $60-90 \mu \mathrm{mol} / \mathrm{l}$. The diet was supplemented with phenylalanine-free amino acids (100-180 g/day) and tyrosine (0-5 g/day). Plasma amino acid concentrations were monitored weekly by amino acid analyser. Dietary phenylalanine intake ranged from $6 \mathrm{mg} / \mathrm{kg} /$ day at conception to $30 \mathrm{mg} / \mathrm{kg} /$ day at delivery. Normal weight gain and fetal growth were maintained throughout the pregnancy. A normal baby was born at term with a head circumference of $35.5 \mathrm{~cm}$; at 1 year of age no abnormality is detectable. These results show that with careful monitoring and compliance it is possible, and may be advisable, to maintain plasma phenylalanine concentration within the normal range in the management of PKU pregnancy.
\end{abstract}

The dietary management of phenylketonuria (PKU) both in infancy and in pregnancy has generally been monitored by measurement of phenylalanine concentrations using filter paper blood spot specimens. The limited reliability of these measurements at low phenylalanine concentration and the importance of avoiding phenylalanine deficiency have led to generally accepted therapeutic ideal ranges for plasma phenylalanine concentration of between $200-400 \mu \mathrm{mol} / 1$ in children under 8 years ${ }^{1}$ and between $120-360 \mu \mathrm{mol} / 1$ during pregnancy. ${ }^{2}$ Preconceptional and gestational control of phenylalanine concentrations within these limits in maternal PKU generally results in offspring having an intelligence quotient (IQ) and developmental quotient within the normal range. ${ }^{3}$ As yet there are insufficient data to conclude that mean IQ is the same as that of the general population.

The concentration gradient across the human placenta results in the fetus being exposed to phenylalanine concentrations approximately twice those in maternal plasma. ${ }^{45}$ The developing fetal brain is likely to be at least as sensitive, if not more so, to damage by increased phenylalanine concentrations as that of the infant. These considerations would favour maintenance of maternal phenylalanine concentration at or below $50 \%$ of the recommended treatment range for infancy. This concept is taken further by regression data of phenylalanine concentration at conception in women with PKU against head circumference of offspring. ${ }^{6}$ These data have recently been extended to show that head circumference at birth falls by $0.46 \mathrm{~cm}$ for every $200 \mu \mathrm{mol} / 1$ rise in phenylalanine concentration above normal. ${ }^{7}$ It has therefore been suggested that plasma phenylalanine concentration should be maintained in the normal range throughout pregnancy in a woman with PKU. ${ }^{7}$

We now report management and outcome of pregnancy in a woman with PKU using these principles. The limited sensitivity of the filter paper blood spot assay method ${ }^{8}$ led us to use the more precise method of automated amino acid analysis to monitor plasma amino acid concentrations, aiming for a therapeutic control range for phenylalanine of between $50-150 \mu \mathrm{mol} / \mathrm{l}$ and for tyrosine of between $60-90 \mu \mathrm{mol} / 1$ (that is, within the upper normal range). The rationale for control of tyrosine concentration was based on the remarkable inhibition of tyrosine transport into placental brush border membrane vesicles with increasing concentrations of phenylalanine. 9

\section{Case history}

The patient was born in 1962 before the commencement of neonatal screening programmes for PKU in Australia. She first presented at the age of 2.5 years because of slow development and had a phenylalanine concentration of $1800 \mu \mathrm{mol} / \mathrm{l}$. She was subsequently treated with a protein restricted, phenylalaninefree amino acid supplemented diet until the age of 9 years. Serial developmental assessments into teenage years placed her IQ in the lownormal range. Subsequent progress was uneventful until, at the age of 27 years, she planned pregnancy.

Dietary treatment was commenced 10 weeks before conception. The principles of the dietary regimen are summarised in the table. Phenylalanine-free amino acids, vitamins, and minerals were supplemented using a proprietary formulation (Maxamum XP, Scientific Hospital Supplies). An initial dose of $150 \mathrm{~g} /$ day was increased to $180 \mathrm{~g} /$ day at 24 weeks' gestation and subsequently decreased at 37 weeks to 
Principles of dietary management of maternal phenylketonuria aiming for normal plasma phenylalanine concentrations

\begin{tabular}{|c|c|c|}
\hline & Before pregnancy & During pregnancy \\
\hline Protein (as natural protein + amino acids) & $<0.75 \mathrm{~g} / \mathrm{kg}$ & $<0.75 \mathrm{~g} / \mathrm{kg}+6 \mathrm{~g}$ \\
\hline Phenylalanine & $\begin{array}{l}\text { Initially } 4-8 \mathrm{mg} / \mathrm{kg},{ }^{*} \text { adjust as } \\
\text { indicated to maintain } \\
\text { therapeutic range }\end{array}$ & $\begin{array}{c}\text { Increase with } \\
\text { advancing gestation } \\
\text { to maintain therapeutic range }\end{array}$ \\
\hline Tyrosine & $\begin{array}{l}\text { Initially } 160 \mathrm{mg} / \mathrm{kg} \text {; adjust as } \\
\text { indicated to maintain } \\
\text { therapeutic range }\end{array}$ & $\begin{array}{c}\text { Increase with } \\
\text { advancing gestation } \\
\text { to maintain therapeutic range }\end{array}$ \\
\hline Calcium & $800 \mathrm{mg}$ & $\begin{array}{l}1100 \mathrm{mg} \text { first and second trimester, } \\
1300 \mathrm{mg} \text { third trimester }\end{array}$ \\
\hline Iron & $12-16 \mathrm{mg}$ & $22-36 \mathrm{mg}$ \\
\hline Zinc & $12-16 \mathrm{mg}$ & $16-21 \mathrm{mg}$ \\
\hline Folic acid (as total folate) & $200 \mu \mathrm{g}$ & $400 \mu \mathrm{g}$ \\
\hline Macro and micro minerals and vitamins & \multicolumn{2}{|c|}{$\begin{array}{l}\text { Full range supplied from natural foods, protein } \\
\text { substitutes, and supplements }\end{array}$} \\
\hline Essential fatty acids and cholesterol & \multicolumn{2}{|c|}{ From dietary fats and oils } \\
\hline Energy & $\begin{array}{l}\text { Individual assessment based } \\
\text { on age, weight, appetite, activity }\end{array}$ & $\begin{array}{l}\text { Add } 850-1100 \mathrm{~kJ} \text { to } \\
\text { prepregnancy requirement }\end{array}$ \\
\hline Weight gain & & $\begin{array}{l}\text { First } 12 \text { weeks: } 1-2 \mathrm{~kg} \\
\text { Then } 1-2 \mathrm{~kg} / \text { month to term }\end{array}$ \\
\hline Plasma phenylalanine & $\begin{array}{l}\text { Monitor weekly, } \\
\text { maintain } 75-150 \mu \mathrm{mol} / \mathrm{l} \text { for four weeks } \\
\text { before ceasing contraception }\end{array}$ & $\begin{array}{l}\text { Monitor weekly, } \\
\text { maintain } 75-150 \mu \mathrm{mol} / 1\end{array}$ \\
\hline Tyrosine & $\begin{array}{l}\text { Monitor weekly, } \\
\text { maintain } 60-90 \mu \mathrm{mol} / \mathrm{l} \text { for four weeks } \\
\text { before ceasing contraception }\end{array}$ & $\begin{array}{l}\text { Monitor weekly, } \\
\text { maintain } 60-90 \mu \mathrm{mol} / \mathrm{l}\end{array}$ \\
\hline
\end{tabular}

Intakes are given as daily requirements. ${ }^{10-12}$

$100 \mathrm{~g} /$ day as natural protein intake increased. The daily intake was divided into three equal portions and was taken with meals.

Changes in phenylalanine concentration in relation to dietary phenylalanine intake are shown in fig 1 . Blood phenylalanine concentrations were monitored before conception and in the first four weeks after conception using filter paper blood spots and the bacterial inhibition assay; full amino acid chromatograms were obtained intermittently during this period. Subsequently, plasma phenylalanine and tyrosine

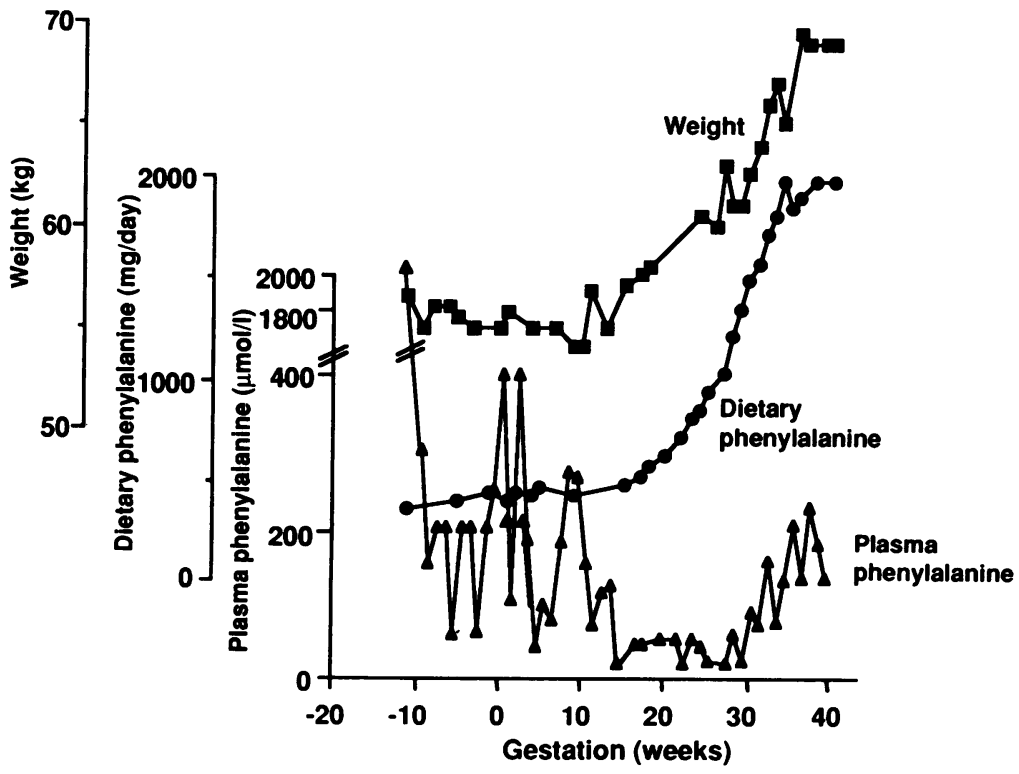

Figure 1 Dietary phenylalanine intake, plasma phenylalanine concentration, and maternal weight gain before and during pregnancy. Minimum phenylalanine concentration was $15 \mu \mathrm{mol} / \mathrm{l}$ at 22 weeks' gestation. concentrations were monitored weekly by amino acid analyser (Biotronik LC 5000) because of concern over the precision of filter paper methods and the need to measure tyrosine concentration. All blood specimens were collected preprandially to simulate conditions under which the normal ranges were established. Blood was centrifuged and plasma separated immediately after collection. Plasma was then transported to reach our laboratory on the day of collection. After commencing treatment, the phenylalanine concentration rapidly fell to a little above the desired therapeutic range of $50-150 \mu \mathrm{mol} / 1$. The patient's limited intelligence and her domicile in country Victoria, which restricted regular visits to the Royal Children's Hospital, made communication less than optimal on a number of occasions during the pregnancy. In mid-trimester plasma phenylalanine concentrations fell below the desired range several times, the lowest being $18 \mu \mathrm{mol} / 1$ at 15 weeks and $15 \mu \mathrm{mol} / \mathrm{l}$ at 22 weeks. These low concentrations may have been avoided through better communication. Plasma tyrosine concentrations (fig 2) were generally maintained close to or within the desired therapeutic range of $60-90 \mu \mathrm{mol} / \mathrm{l}$. Tyrosine intake from natural protein, Maxamum XP, and additional tyrosine supplements is also shown in fig 2 . The need for tyrosine supplementation additional to that provided by Maxamum XP and natural protein varied between 0 and $5 \mathrm{~g} /$ day; this was taken in three divided doses with Maxamum XP.

Maternal weight gain (fig 1) was satisfactory throughout the pregnancy, although there was some weight loss in the first trimester. Compliance with energy supplements in the form of 


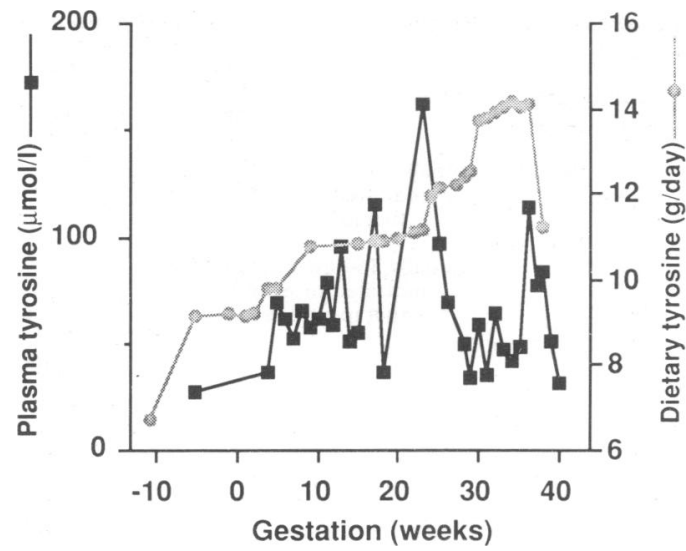

Figure 2 Tyrosine concentration in relation to intake before and during pregnancy.

low protein pastas and breads was poor at certain points during the pregnancy including the first trimester. Fetal growth was monitored by ultrasound examination at 18,28 , and 36 weeks of gestation. Despite suboptimal maternal energy intake and occasional subtherapeutic phenylalanine concentrations, fetal growth was normal throughout the pregnancy. Ultrasound examinations revealed no evidence of malformation.

There were no obstetric complications throughout the pregnancy and the baby was born by normal delivery at 41 weeks' gestation. Birth weight was $3920 \mathrm{~g}$ (75th centile), length $51.0 \mathrm{~cm}$ (50-75th centile), and head circumference $35.5 \mathrm{~cm}(50-75$ th centile). The baby is quite normal to physical examination and now, at 12 months of age, has a Bayley developmental index (mental scale) of 106. Head circumference continues to lie on the 75 th centile, weight on the 50 th, and length on the 75 th.

\section{Discussion}

The potentially disastrous effects of phenylalanine deprivation, ${ }^{13}$ the poor reliability of filter paper blood spot assay of low phenylalanine concentration, ${ }^{8}$ and the apparently good outcome of PKU treated by maintaining plasma phenylalanine concentration a little above normal, ${ }^{14}$ have led to the great reluctance to maintain phenylalanine concentrations in children with PKU within the normal range. While mounting circumstantial evidence suggests that plasma phenylalanine concentrations should be better controlled during pregnancy than is necessary for treatment of childhood $\mathrm{PKU},{ }^{7}$ the exact optimal range is yet to be determined. We have demonstrated that the accuracy of amino acid analyser determinations of plasma phenylalanine and tyrosine concentration can result in very precise control of blood phenylalanine and tyrosine in PKU. The therapeutic range aimed for in this patient (phenylalanine 50-150 $\mu \mathrm{mol} / \mathrm{l}$, tyrosine 60 $90 \mu \mathrm{mol} / \mathrm{l})$ overlaps with that for normal pregnancy (phenylalanine 66-107 $\mu \mathrm{mol} / 1$, tyrosine 40-76 $\mu \mathrm{mol} / 1, \mathrm{n}=7$, second trimester, personal communication, Dr E F Robertson).
No abnormality has been detected in the baby born to our patient. Head circumference measurements appear to be a sensitive indicator of outcome in maternal $\mathrm{PKU}^{6}$ and on this measure the baby is normal. This conclusion is supported by a normal developmental assessment at 1 year of age. Nevertheless, complete evaluation of the strategy of maintaining normal phenylalanine concentration in maternal PKU will not be possible until a much larger number of cases similar to ours have been described and followed up long term.

At several points during the current pregnancy, compliance and communication difficulties resulted in phenylalanine concentrations falling outside the intended therapeutic range. Early in the pregnancy concentrations rose to 271 and $266 \mu \mathrm{mol} / 1$ at 9 and 10 weeks' gestation respectively. In a second pregnant PKU patient currently under treatment by the authors the phenylalanine concentration was well controlled before conception with a dietary phenylalanine intake of about $4 \mathrm{mg} / \mathrm{kg} / \mathrm{day}$, but the concentration rose to about $200 \mu \mathrm{mol} / 1$ in the middle of the first trimester. In both patients the first trimester increases most likely reflected difficulty in maintaining energy intake because of morning sickness of pregnancy. Our experience in conventional management of PKU pregnancy indicates that phenylalanine concentrations can be difficult to control in the first trimester. In the patient currently under treatment, control of the phenylalanine concentration within the desired range was obtained when an energy supplement in the form of glucose polymer (Polyjoule, Sharpe Laboratories, 100 g/day) was added to the regimen.

Very low phenylalanine concentrations were also documented on several occasions, despite which no symptoms of phenylalanine deficiency were noted in the mother and the baby continued to grow satisfactorily. The ability to concentrate phenylalanine across the placenta in favour of the fetus ${ }^{5}$ may protect the fetus from the effects of borderline maternal phenylalanine deficiency. Nevertheless, the potential risks of low phenylalanine concentration indicate the need for careful attention to increasing phenylalanine requirements, particularly during the second trimester. The narrow therapeutic range also requires accurate calculation of all dietary sources of phenylalanine including low phenylalanine bread, pasta, and biscuits and fruits and vegetables. Some of these foods are permitted without measurement in the diet of children with PKU on the basis that an average consumption provides a relatively constant intake of phenylalanine.

Tyrosine is a neurotransmitter precursor and low neurotransmitter concentrations have been suggested as one of the mechanisms by which damage may occur in PKU. ${ }^{16}$ An optimal range for plasma tyrosine concentration in pregnancy of a woman with PKU has not been established. The potential for even small rises in plasma phenylalanine concentration to inhibit placental tyrosine transport ${ }^{8}$ suggests that maintenance of tyrosine concentrations in the upper normal range may be ideal. Treatment with a tyrosine fortified formula such as Maxamum XP with 
additional tyrosine supplements as required seems a satisfactory approach. The tyrosine concentration bore no consistent relationship to that of phenylalanine, presumably because the intake of each respective amino acid was adjusted independently in response to changes in blood concentrations. An unusually high tyrosine concentration $(162 \mu \mathrm{mol} / \mathrm{l})$ was recorded at 23 weeks. There was no clear explanation for this increase. However, it is likely that the concentration was even higher one to two hours postprandially on this occasion and the possibility that raised tyrosine concentrations may in themselves cause fetal damage should not be ignored. ${ }^{17}$ Excessive tyrosine supplementation should be avoided.

In summary, we have now documented for the first time implementation of a frequently discussed strategy of maintaining normal phenylalanine concentrations in maternal PKU. Early indications suggest a normal outcome, although long term follow up of this and subsequent cases will be needed to determine the advantages of this strategy as compared with those of more conventional treatment methods. Our experience coupled with solid theoretical background suggests that these further studies should be undertaken.

1 Guttler F, Lou H. Phenylketonuria and hyperphenylalaninemia. In: Fernandes J, Saudubray JM, Tada K, eds. Inborn metabolic disease: diagnosis and treatment. Berlin: Springer-Verlag, 1990:161-74.

2 Koch $\mathrm{R}$, Hanley W, Levy $\mathbf{H}$, et al. A preliminary report of the collaborative study of maternal phenylketonuria in the United States and Canada. F Inherited Metab Dis 1990;13: 641-50.
3 Guttler F, Lou H, Andresen J, et al. Cognitive development in offspring of untreated and preconceptionally treated maternal phenylketonuria. $\mathcal{F}$ Inherited Metab Dis 1990;13: maternal

4 Brenton DP, Haseler ME. Maternal phenylketonuria. In: Fernandes J, Saudubray JM, Tada K, eds. Inborn metabolic disease: diagnosis and treatment. Berlin: Springer-Verlag,

5 Soltesz G, Harris D, MacKenzie Z, Aynsley-Green A. The metabolic and endocrine milieu of the human fetus and mother at 18-21 weeks of gestation. I. Plasma amino acids concentrations. Pediatr Res 1985;19:1.

6 Drogari E, Smith I, Beasley M, Lloyd JK. Timing of strict diet in relation to fetal damage in maternal phenylketonuria. Lancet 1987; ii:927-30.

7 Smith I, Glossop J, Beasley M. Fetal damage due to maternal phenylketonuria: effects of dietary treatment and maternal phenylalanine concentrations around the time of conception (an interim report from the UK phenylketonuria register). I Inherited Metab Dis 1990;13:651-7.

8 Spierto FW, Hearn TL, Gardner FH, Hannon WH. Phenylalanine analyses of blood-spot control materials: preparation of samples and evaluation of interlaboratory performance. Clin Chem 1985;31:235-8.

9 Kudo Y, Boyd CAR. Transport of amino acids across the blood-brain barrier: implications for treatment of maternal phenylketonuria. F Inherited Metab Dis 1990;13:617-26.

10 Dreosti IE. Recommended dietary intake for protein in Australia. Australian fournal of Nutrition and Dietetics 1989;46:82-92.

11 Truswell SA. Recommended nutrient intakes - Australian papers. Sydney: Australian Professional Publications, 1990.

2 Warwick PM. Predicting food energy requirements for estimates of energy expenditure. Australian foumal of Nutrition and Dietetics 1989;46 (suppl):S3-28.

13 Hanley WB, Linsao L, Davidson W, Moes CAF. Malnutrition with early treatment of phenylketonuria. Pediatr Res 1970;4:318-27.

14 Michals K, Azen C, Acosta P, Koch R, Matalon R. Blood phenylalanine levels and intelligence of 10 year old children phenylalanine levels and intelligence of 10 year old children
with PKU in the national collaborative study. 7 Am Diet with PKU in the nation

15 Pietz J, Benninger C, Schmidt H, Scheffner D, Bickel $\mathbf{H}$. Long-term development of intelligence (IQ) and EEG in 34 children with phenylketonuria treated early. Eur $\mathcal{f}$ Pediatr 1988;147:361-7.

16 Heather G. Amino acid availability and brain development: effects of nutritional and metabolic inadequacies. Eur $\dot{\mathcal{J}}$ Clin Nutr 1989;43:19-25.

17 Lewis SA, Lyon ICT, Elliott RB. Outcome of pregnancy in the rat with mild hyperphenylalanaemia and hypertyrosinaemia: implications for the management of "human maternal PKU'. F Inherited Metab Dis 1985;8:113-7. 